\title{
Aspectos Morfológicos e Morfométricos do Colo Uterino de Ratas Ooforectomizadas após Aplicação de Óleo de Copaiba
}

\author{
Morphological and Morphometric Aspects of the Uterine Cervix in Oophorectomized \\ Rats after Copaíba Oil Application
}

\begin{abstract}
Nara Macedo Botelho Brito ${ }^{1}$, Luiz Kulay-Júnior ${ }^{2}$, Manuel de Jesus Simões ${ }^{3}$, Osmar Alves Lameira ${ }^{4}$, Luciana Garcia Lamarão ${ }^{5}$, Sérgio Henrique Bastos Damous ${ }^{5}$
\end{abstract}

\begin{abstract}
RESUMO
Objetivos: verificar o efeito do óleo de copaíba no colo uterino de ratas ooforectomizadas. Métodos: foram utilizadas 120 ratas adultas distribuidas em 4 grupos: as que receberam aplicação de óleo de copaíba, óleo de milho, água e um grupo sem tratamento. Todos os animais foram submetidos a ooforectomia bilateral e posteriormente mantidos em gaiolas por um periodo de 20 dias antes de iniciar a aplicação das substâncias. Estas foram administradas via vaginal na dose de 0,3 $\mathrm{ml}$, diariamente, uma vez ao dia até os dias determinados para o sacrificio $\left(7^{\circ}\right.$, $14^{\circ}$ e $21^{\circ}$ ), sendo sacrificados de cada grupo 5 animais por dia.

Resultados: todos os animais do grupo copaíba apresentaram epitélio exuberante, estratificado pavimentoso queratinizado, em torno de 10 fileiras de células epiteliais, e lâmina própria com tecido conjuntivo denso, rico em fibroblastos, fibras colágenas, inúmeros vasos sanguineos e alguns leucócitos.

Conclusões: o óleo de copaíba utilizado neste modelo experimental promoveu espessamento do epitélio do colo uterino, que se apresentava pavimentoso estratificado com queratinização, além do espessamento progressivo deste epitélio no decorrer dos dias de estudo.
\end{abstract}

PALAVRAS-CHAVE: Óleo de copaíba. Colo do útero. Modelos experimentais.

\section{Introdução}

A Medicina natural tem se mostrado como alternativa para o tratamento de doenças pela população ${ }^{1,2}$, que utiliza muitas plantas oriundas da Amazônia, embora desconheça o pouco que se sabe a respeito de seus princípios ativos, mecanismos de ação e toxicidade ${ }^{3,4}$.

Uma substância que tem assumido grande

Trabalho realizado no Laboratório de Cirurgia Experimental da Universidade do Estado do Pará com apoio do Instituto Evandro Chagas e financiado pelo FUNTEC/SECTAM-PA.

${ }^{1}$ Departamento de Saúde Especializada. Universidade do Estado do Pará (UEPA).

${ }^{2}$ Disciplina de Obstetrícia de Tocoginecologia. Universidade Federal de São Paulo - Escola Paulista de Medicina (UNIFESP EPM).

${ }^{3}$ Departamento de Morfologia. UNIFESP - EPM

${ }^{4}$ EMBRAPA - Amazônia Oriental.

${ }^{5}$ Laboratório de Cirurgia Experimental. UEPA.

Correspondência: Nara Macedo Botelho Brito

Tv. Apinagés, 630 - apto 201

66033-170 - Belém - PA

Fone: (91) 242-5179 / 9982-2030 importância neste contexto de Medicina natural é um óleo extraído de árvores do gênero Copaifera, da família Leguminosae-Caesalpinioideae e conhecido como óleo de copaíba ${ }^{4-14}$.

Este óleo se destaca por suas supostas propriedades terapêuticas não só na Amazônia mas também no nordeste brasileiro, sendo inclusive exportado para outros países em virtude de sua ampla indicação para enfermidades como cistites, bronquites, diarréia crônica, reumatismo e psoriase, além de efeitos antitetânico, antiblenorrágico, anticatarral e cicatrizante ${ }^{3,12,14-18}$.

Em razão do pouco conhecimento acerca dos princípios ativos, ação e toxicidade do óleo de copaíba ${ }^{15}$ e por sua ampla utilização empírica em tratamentos ginecológicos como cervicite, leucorréia ${ }^{7,13}$ e blenorragia ${ }^{4,7,9,10,13,16,17}$, o presente trabalho tem como objetivo estudar o efeito desta substância sobre o epitélio do colo uterino de ratas ooforectomizadas. 
Métodos

Foram utilizadas 120 ratas (Rattus norvegicus albinus, Rodentia Mammalia) virgens, adultas, com peso entre 200 e $250 \mathrm{~g}$, oriundas do Biotério do Instituto Evandro Chagas de Belém, PA e adaptadas ao Laboratório de Cirurgia Experimental da Universidade do Estado do Pará por um período de 15 dias, recebendo água e ração ad libitum durante todo o experimento.

Os animais foram distribuídos em 4 grupos de estudo constituídos por 30 animais cada: grupo água, grupo milho e grupo copaíba, conforme a substância a ser aplicada, e ainda um grupo controle constituído por animais que não receberam tratamento. Todos os animais foram subdivididos em 3 subgrupos com 10 animais cada de acordo com a data determinada para o sacrifício, padronizadas como 7, 14 e 21 dias após o início do tratamento.

Os animais foram submetidos a ooforectomia bilateral por via ventral sob anestesia inalatória com éter etílico. Após isso, foram então mantidos em gaiolas com ambiente controlado por 20 dias, para então ser iniciada a aplicação da substância de acordo com o grupo a que pertencesse.

No $21^{\circ}$ dia após a ooforectomia, ou seja, no dia zero do experimento (D0), foi colhido conteúdo do terço inferior da vagina, utilizando-se hastes com algodão embebido em solução salina a $0,9 \%^{18,19}$.

Após colhido, o material foi distribuído sobre lâmina, sendo então mergulhada em solução de álcool absoluto para posterior coloração pelo método de Harris-Shorr ${ }^{18,20}$.

Nos grupos água, milho e copaíba, foram aplicados respectivamente água destilada esterilizada, óleo de milho e óleo de copaíba na sua forma pura. De acordo com a distribuição de cada grupo, foi aplicado por via vaginal $0,3 \mathrm{ml}$ da substância correspondente, utlizando-se seringas descartáveis.

No grupo controle não foi aplicada nenhuma substância, sendo os animais submetidos apenas a ooforectomia para posterior estudo do colo uterino.

O óleo de milho utilizado foi adquirido comercialmente e era composto por gorduras poliinsaturadas, monoinsaturadas e saturadas. A cultura para cocos e bacilos apresentou-se negativa. Quanto à análise físico-química, foi observado indice de acidez $0,27 \%$, indice de saponificação $191 \mathrm{mg} \%$, índice de refração 1,465, índice de iodo 113 e índice de peróxido 17,7 $\mathrm{mEq} / \mathrm{kg}$.
O óleo de copaíba utilizado foi da espécie Copaifera reticulata Ducke, proveniente da Empresa Brasileira de Pesquisa Agropecuária (EMBRAPA - Amazônia Oriental). Este óleo foi submetido a cultura e análise físico-química e criptográfica. A cultura foi negativa para o crescimento de cocos e bacilos. Na análise criptográfica da amostra foi evidenciada a presença de três subclasses terpenóides: sesquiterpenos hidrocarbonados, sesquiterpenos oxigenados e diterpenos. A análise físico-química evidenciou indice de acidez $79,2 \%$, indice de saponificação $82,3 \mathrm{mg} \%$, índice de refração 1,515 , índice de iodo 184,4 e índice de peróxido $5,4 \mathrm{mEq} / \mathrm{kg}$.

Os animais foram submetidos ao sacrificio em data pré-determinada (7, 14 e 21 dias), por meio de dose inalatória letal de éter etílico, seguido de incisão mediana xifopubiana, com disjunção da sínfise para facilitar a remoção em bloco dos cornos uterinos, colo e vagina. Esta foi seccionada em seu terço distal e aberta longitudinalmente na linha média anterior, expondo o colo uterino.

Os cornos uterinos foram seccionados transversalmente no seu ponto de bifurcação ${ }^{18,20}$. Após ressecção, as peças foram fixadas em formol a $10 \%$ por um período de 7 dias, sendo em seguida submetidas ao processamento histológico de rotina para inclusão em parafina. Os cortes foram obtidos em micrótomo ajustado para 5 micra e, posteriormente, corados pela hematoxilina-eosina e examinados em microscópio óptico em objetivas de 4 e 10 vezes de aumento.

A medida da espessura do epitélio do colo uterino foi realizada com uma régua milimetrada de $1 \mathrm{~cm}$, excetuando-se as lamelas queratinizadas. Foram medidos os 10 pontos mais estreitos do epitélio em cada lâmina.

O estudo estatístico foi realizado no Departamento de Medicina Preventiva, Disciplina de Bioestatística da UNIFESP - EPM, sendo utilizados o teste de Kruskal-Wallis com o objetivo de comparar os grupos de estudo em cada tempo do experimento. O nível de rejeição da hipótese de nulidade foi fixado em 0,05 ou $5 \%$.

\section{Resultados}

Todos os animais dos grupos estudados apresentaram no $21^{\circ}$ dia colpocitologia com escassez de elementos celulares de origem epitelial e grande concentração de leucócitos. Houve predominio, entre as células epiteliais, de células de pequeno diâmetro, núcleo grande, central 
e vesiculoso com citoplasma basófilo, características da camada basal. Estavam presentes, ainda, algumas células da camada intermediária. As células acidófilas, características da camada superficial, eram raras e apresentavam preservação do núcleo e, em algumas, havia sinais de degeneração. Foi observado ainda aumento da concentração de muco.

Os resultados morfológicos de todos os animais dos grupos controle, água e milho apresentaram epitélio com 1 a 2 fileiras de células epiteliais, sendo a mais superficial cúbica ou cilindrica simples (dependendo do corte), núcleo arredondado e central. A lâmina própria se mostrava pouco desenvolvida, havendo muitos fibroblastos com núcleo picnótico, tecido conjuntivo denso e fibras colágenas (Figura 1).

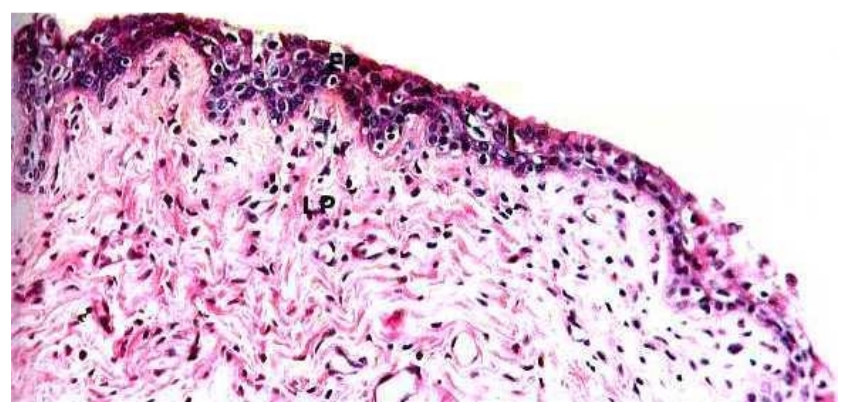

Figura 1 - Epitélio (EP) e lâmina própria (LP) de corte do colo uterino da rata do grupo controle no $7^{\circ}$ dia. Verificar a camada epitelial com 1 a 2 fileiras de células. HE (280X).

Com relação aos animais do grupo copaíba, em todos, qualquer que fosse o dia de estudo, o epitélio era exuberante, estratificado pavimentoso queratinizado com cerca de 10 fileiras de células epiteliais. A lâmina própria era constituida de tecido conjuntivo denso, rico em fibroblastos, fibras colágenas, com inúmeros vasos sanguíneos e alguns leucócitos (Figura 2).

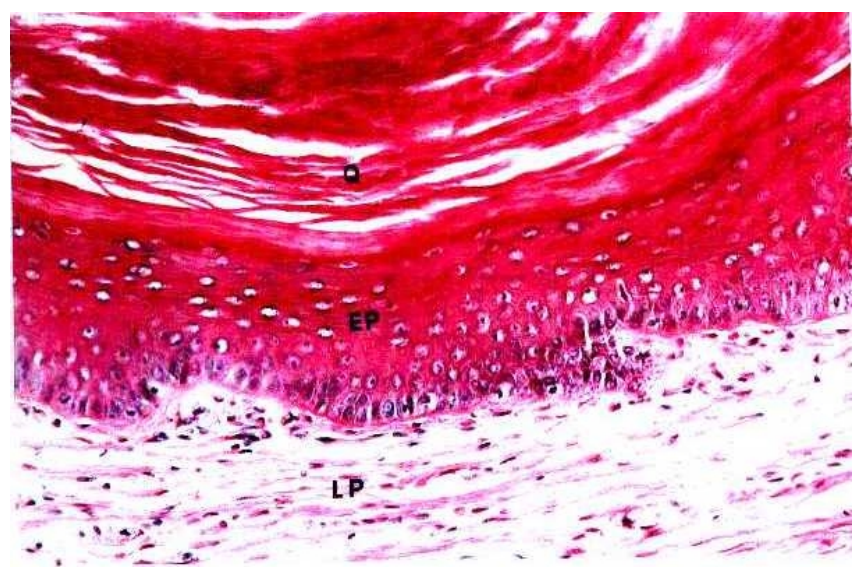

Figura 2 - Epitélio (EP) e lâmina própria (LP) de corte do colo uterino da rata do grupo copaíba no $7^{\circ}$ dia, com epitélio pavimentoso estratificado e queratinizado (Q) bem desenvolvido. $\mathrm{HE}(280 \mathrm{X})$.
A análise morfométrica da espessura do epitélio do colo uterino da rata mostrou que no grupo copaíba houve diferença estatisticamente significante quando comparado aos outros grupos do experimento $(\mathrm{p}<0,05)$ (Figura 3$)$.

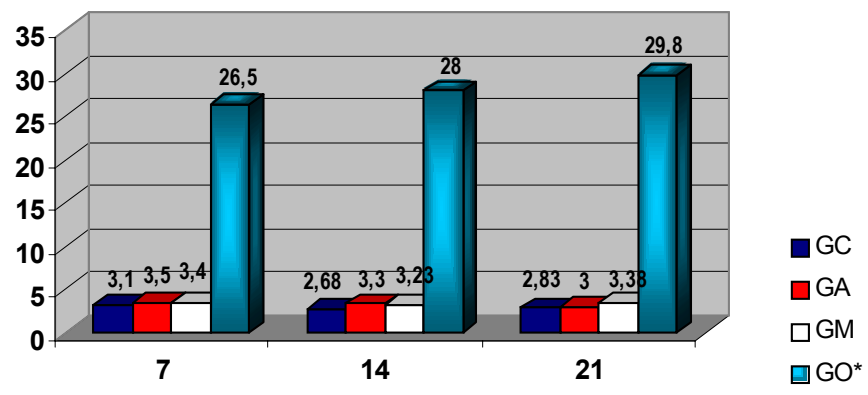

Figura 3-Medidas da espessura do epitélio do colo uterino de ratas ooforectomizadas nos grupos controle (GC), água (GA), milho (GM) e copaíba (GO), conforme os dias de estudo $\left(7^{\circ}, 14^{\circ} \mathrm{e} 21^{\circ}\right)$. ${ }^{*} p<0,05$-Kruskal-Wallis.

\section{Discussão}

O óleo de copaíba é uma destacada substância medicinal de uso popular, em especial na Amazônia, como antiinflamatório, cicatrizante e antiinfeccioso pelas vias oral, tópica ou vaginal $^{3-5,9,10,12,13,16,21-23}$.

Embora seja de uso difundido tanto entre a população quanto no meio médico, pouco se conhece a respeito de seu efeito quando aplicado pela via vaginal para o tratamento de cervicites e corrimentos.

Com finalidade de estudar os seus efeitos, os animais foram distribuídos no presente estudo de tal forma que o grupo controle determinasse parâmetros de normalidade, visto que foram submetidos apenas à ooforectomia bilateral e ao sacrificio, e o grupo água, no qual foi aplicada água esterilizada, avaliasse possiveis alterações decorrentes da manipulação e/ou aplicação da substância. A administração do óleo de milho teve como finalidade observar se as modificações encontradas seriam em decorrência do(s) princípios(s) ativo(s) do óleo de copaíba ou devido à característica oleosa da substância.

Com o intuito de minimizar a possibilidade de influência de fatores hormonais presente no ciclo estral dos animais, foi realizada ooforectomia bilateral para que, desta forma, todos os animais ficassem em anestro, uniformizando a amostra. O intervalo de 20 dias entre a ooforectomia e a aplicação das substâncias se deveu ao fato de que, após este período, já haveriam cessado os efeitos hormonais sobre o colo uterino ${ }^{18}$. 
O óleo de copaíba utilizado foi proveniente de árvores da espécie Copaifera reticulata Ducke, a mais importante do ponto de vista comercial, uma vez que desta é extraído $70 \%$ de todo o óleo comercializado no Brasil ${ }^{7,10,12,14}$.

O óleo foi aplicado em sua forma in natura, pois é desta maneira que o mesmo é utilizado pela população, tendo sido realizadas cultura, análise físico-química e criptográfica para se conhecer seus componentes.

A coleta de material para colpocitologia permitiu concluir, de acordo com as características deste material, que os animais realmente se encontravam em anestro. Estes achados coincidiram com os de Mora ${ }^{20}$, Bacci ${ }^{18}$ e Hamilton ${ }^{24}$.

O colo uterino nos grupos padrão, água e milho, de estudo mostrou em todos os dias resultados semelhantes aos descritos por Hamilton $^{24}$ e Bacci $1^{18}$, com epitélio atrófico de 1 ou 2 fileiras de células. No grupo copaíba, porém, observou-se um epitélio exuberante, pavimentoso estratificado queratinizado, quer seja no $7^{\circ}, 14^{\circ}$ ou $21^{\circ}$ dia de estudo.

Este epitélio exuberante não deveria estar presente, pois o animal não estava sob ação de estrogênio, o que foi confirmado na leitura da colpocitologia no $21^{\circ}$ dia após a ooforectomia. Para induzir tal epitelização, o óleo de copaíba pode ter agido por um efeito pseudo-hormonal, por ação de princípio(s) ativo(s) ou por irritação tópica. Este efeito irritante já havia sido evidenciado por Brito $^{25}$ ao estudar a cicatrização após aplicação tópica de óleo de copaíba em feridas cutâneas abertas em ratos.

Brito et $a l .{ }^{26}$, por sua vez, ao estudar o efeito deste óleo no comportamento de ratos, observaram agressividade do animal possivelmente decorrente do odor irritativo e ação cáustica.

Na lâmina própria, os aspectos morfológicos dos grupos controle, água e milho nos dias $7^{\circ}, 14^{\circ}$ e $21^{\circ}$, em relação ao grupo copaíba no $7^{\circ}$, $14^{\circ}$ e $21^{\circ}$ dias, revelaram resultados semelhantes aos descritos por Hamilton ${ }^{24}$ e Bacci ${ }^{18}$. Desta forma, constatou-se que o óleo de copaíba não demonstrou ação importante sobre esta camada.

O estudo morfométrico da espessura do epitélio do colo uterino revelou que os grupos controle, água e milho no $7^{\circ}, 14^{\circ}$ e $21^{\circ}$ dias não apresentaram diferenças estatisticamente significantes considerando-se os tratamentos e os períodos de coleta da amostra. Quanto ao grupo copaíba nos mesmos dias de estudo, pôde-se observar um epitélio bem mais exuberante em relação aos demais grupos, confirmando a ação deste sobre o epitélio. Quando comparados os subgrupos entre si (copaíba $7^{\circ}, 14^{\circ}$ ou $21^{\circ}$ ) foi constatada tendência ao espessamento progressivo do epitélio do colo uterino.

Destaca-se que no grupo copaíba houve aumento do número de fileiras de células no epitélio em relação aos outros grupos, observando-se também a presença de células queratinizadas na superficie.

Por não saber seu mecanismo de ação, outros modelos experimentais são necessários para comprovar estes efeitos, assim como conhecer melhor suas propriedades, pois, embora tenha sido descoberta ação antiinflamatória ${ }^{22}$ do óleo de forma experimental, não foi ainda possível determinar qual ou quais os componentes responsáveis pelas propriedades descritas.

\section{SUMMARY}

Purpose: to study the effect of copaiba oil on the uterine cervix of oophorectomized rats.

Method: 120 female adults were used, divided into four groups: control, water, corn oil and copaiba oil. All animals were submitted to bilateral oophorectomy, and kept in cages for twenty days before applying the substances. These substances were applied by vaginal route at a dose of $0.3 \mathrm{ml}$, once a day until the predetermined day of sacrifice (7, 14 e 21 days).

Results: the animals from the copaiba oil group showed on all days of the study exuberant, keratinous stratified squamous epithelium with about 10 epithelial cell layers and the chorion with conjunctive tissue, fibroblasts, collagen fibers, blood vessels and some leukocytes.

Conclusions: The copaiba oil used in this experimental model promoted a thickening of the epithelium, which was keratinous stratified squamous, and epithelium increase was progressive along the study.

KEY WORDS: Copaiba oil. Uterine cervix. Experimental trials.

\section{Referências}

1. Chaudhury RR. Natural medicinal agents. In: Munson PL, Muller RA, Breese GR, editors. Principles of Pharmacology. New York: Chapman Hall; 1995. p.1529-33.

2. Elisabetsky E. Pesquisa de plantas medicinais. $\mathrm{Ci}$ Cult 1987; 39:697-702. 
3. Basile AC, Sertié JA, Freitas PC, Zanini AC. Antiinflammatory activity of oleoresin from Brazilian Copaifera. J Ethnopharmacol 1988; 22:101-9.

4. Vieira LS. Fitoterapia da Amazônia: manual de plantas medicinais. $2^{a}$ ed. São Paulo: Agronômica Ceres; 1992. p.347.

5. Albuquerque JM. Plantas medicinais de uso popular. 1ª ed.Brasília: ABEAS/MEC; 1989. p.96.

6. Chevalier A. Notes sur 1'origine du Copahu de la région amazonienne. Rev Bot Appl Agric Trop 1952; 12:433-7.

7. Corrêa MP. Dicionário das plantas úteis do Brasil. $1^{\text {a }}$ ed. Rio de Janeiro: Imprensa Nacional; 1978. p.707.

8. Dwyer ID. The Central American, West Indian, and South American species of Copaifera. Brittonia $1951 ; 7: 143-2$.

9. Estrella E. Plantas medicinales Amazônicas: realidad y perspectivas. $1^{\text {a }}$ ed. Lima: TCA; 1995. p.223-4.

10.Fonseca ET. Óleos vegetais brasileiros. $2^{\text {a }}$ ed. Rio de Janeiro: Instituto de Óleos; 1927.

11.Freitas FA, Saraiva MR. Produção e exportação de produtos primários tradicionais: estudo preliminar da economia extrativista do estado do Amazonas. Manaus: Núcleo de Estudos e Projetos; 1992. p.26-30.

12.Guenther E. The essential oils. New York: D. Van Nostrand; 1952. p.850.

13.Pimentel AAMP. Cultivo de plantas medicinais na Amazônia. Belém: FCAP/Serviço de Documentação e Informação; 1994. p.114.

14.Youngken $H$. Tratado de farmacognosia. México: Atlante; 1959. p.556-9.

15.Secco RS. Produtos naturais: alternativa segura? Ci Cult 1990; 42: 807-10.

16.Casamada RSM. Farmacognosia con farmacodinamia. $1^{\text {a }}$ ed. Barcelona: Científico Médica; 1968. p.1121
17.Fernandes J. Sobre o óleo-resina de copaíba e sua aplicação industrial. Associação Comercial do Amazonas. Manaus; 1949.

18.Bacci LC. Contribuição para o estudo morfológico e morfométrico do colo uterino de ratas albinas ooforectomizadas, após administração de estrogênio e ou progestogênio [dissertação]. São Paulo: Universidade Federal de São Paulo; 1988.

19. Hartaman CG. Some new observations on the vaginal smear of the rat. Yale J Biol Med 1944; 17:99-111.

20.Mora AO. Aspectos ultra-estruturais da lâmina própria do colo uterino de ratas albinas em estro, ooforectomizadas e ooforectomizadas tratadas com estrogênio e/ou progesterona [dissertação]. São Paulo: Universidade Federal de São Paulo; 1987.

21.Carvalho PER. Espécies florestais brasileiras: recomendações silviculturais, potencialidades e uso da madeira. Brasília: EMBRAPA - CNPF; 1994.

22.Fernandes RM, Pereira NA, Paulo LG. Antiinflammatory activity of copaiba balsam. Rev Bras Farm 1992; 73:53-6.

23. Maruzzella JC, Sicurella NA. Antibacterial activity of essential oil vapors. J Am Pharm Assoc 1960; 49:692-4.

24.Hamilton CE. The cervix uteri of the rat. Anat Rec 1947; 9:47-62.

25.Brito NB. Aspectos morfológicos e morfométricos da cicatrização de feridas cutâneas abertas em ratos tratados com óleo de copaíba [dissertação]. São Paulo: Universidade Federal de São Paulo; 1995.

26. Brito MVH, Oliveira RVB, Morais MR, Lameira OA. Efeito do óleo de copaíba no comportamento de ratos. Rev Para Med 1999; 13:34-7.

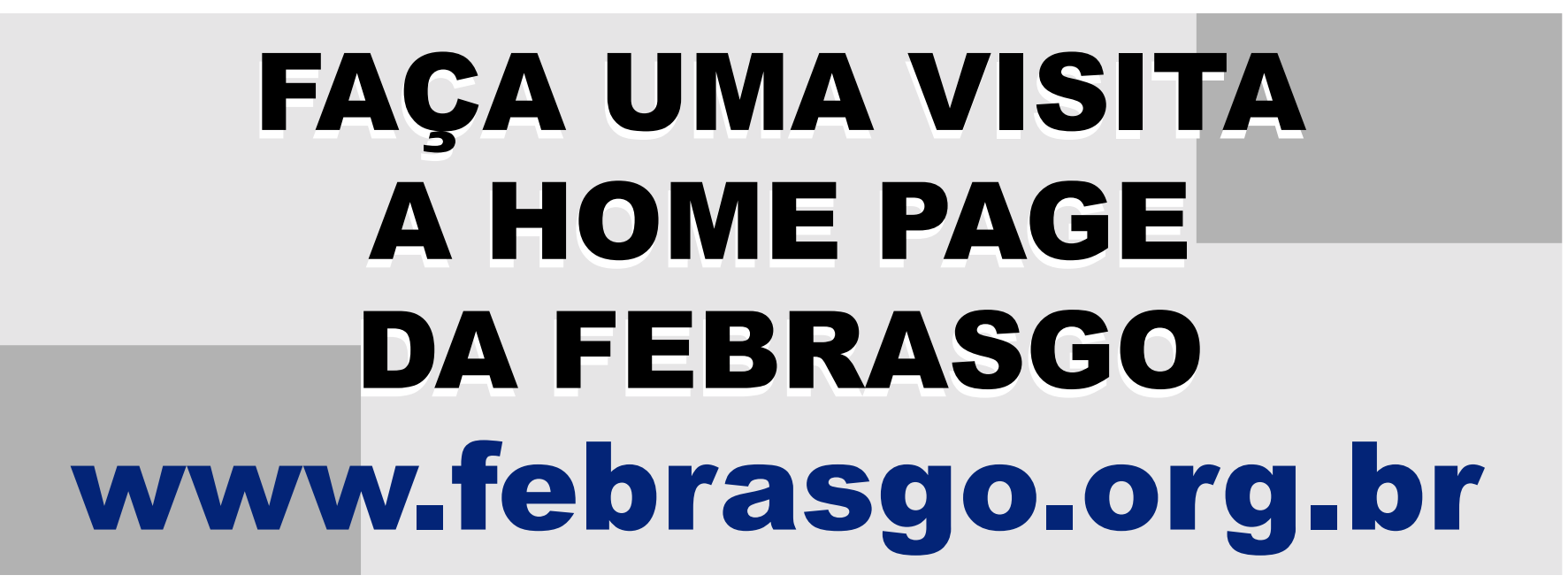

